\title{
Case of a sigmoid colon cancer with metachronous metastases to the mesorectum and the abdominal wall
}

John Kalaitzis*, George Filippou, Adamantia Zizi-Sermpetzoglou, Athanasios Marinis, Andreas Hadjimarcou, Nikolaos Paschalidis, Spyros Rizos

\begin{abstract}
Backround: Sigmoid colon cancer metachronous metastases commonly occur in the liver and lungs with sporadic reports also to the spleen, stomach, thyroid gland, abdominal wall and upper urinary tract. This is a rare case of metachronous metastases invading the mesorectum and the abdominal wall.

Case presentation: A 72-year-old female underwent sigmoidectomy for stage I (T2NO MO) sigmoid colon cancer in May 2008. In June 2009, an abdominal computed tomography scan revealed a tumor $2 \mathrm{~cm}$ in size at the lower anterior mesorectum and a second mass $2 \mathrm{~cm}$ in size at the anterior abdominal wall midline. Total colonoscopy showed no mucosal lesion. The serum carcinoembryonic antigen level was normal. A biopsy of the mesorectum tumor showed similar histologic characteristics with the primary tumor. Since no other site of recurrence was identified, an abdominoperineal resection was attempted. During the operation and after the removal of the incision recurrence, sinus bradycardia and signs of myocardial ischemia were noticed. A loop transverse colostomy was immediately perfomed and the operation was terminated. Postoperative cardiologic examination revealed an acute myocardium infract. Chemo-radiation of the mesorectum tumor and re-evaluation for surgical excision was decided.
\end{abstract}

Conclusion: Metachronous metastasis of the mesorectum from sigmoid colon cancer is extremely rare. Although patterns of lymphatic spread from rectal cancer to sigmoid colon have recently been demonstrated, there is no evidence of metachronous mesorectum invasion from sigmoid colon cancer. This could be the issue for future trials.

\section{Background}

Colon cancer as one of the most commonly diagnosed cancers around the world has an improved prognosis due to the development of diagnostic and therapeutic procedures. Overall survival however, can be seriously shortened, mostly in the presence of distant metastasis during follow-up. Liver is the commonest site of metachronous metastases in approximately one fourth of the patients, followed by the lungs [1]. Sporadic reports also demonstrate the spleen, thyroid gland, stomach, urinary system and abdominal wall as sites of possible reccurence [2-4]. This is a rare case of a sigmoid colon cancer

\footnotetext{
* Correspondence: ianniskal@yahoo.com

1stDepartment of Surgery, General Hospital of Pireus Tzaneio, Athens, Greece
}

with metachronous metastases of the mesorectum and the abdominal wall.

\section{Case Presentation}

A 72-year-old female was admitted to hospital suffering from fatigue, weight loss and rectal bleeding. Total colonoscopy demonstrated adenocarcinoma of the sigmoid colon at $25 \mathrm{~cm}$ from the anal verge. A chest $\mathrm{x}$-ray was normal. No sites of distant metastasis were reported on abdominal computed tomography (CT) scan. The serum carcinoembryonic antigen level was normal. The patient underwent sigmoidectomy in May 2008. During the operation, the left ovary was fixed at the site of the sigmoid colon cancer and was removed en block. Thorough macroscopic examination of the liver and rest of the abdomen showed no sign of metastatic disease. Histopathological examination 


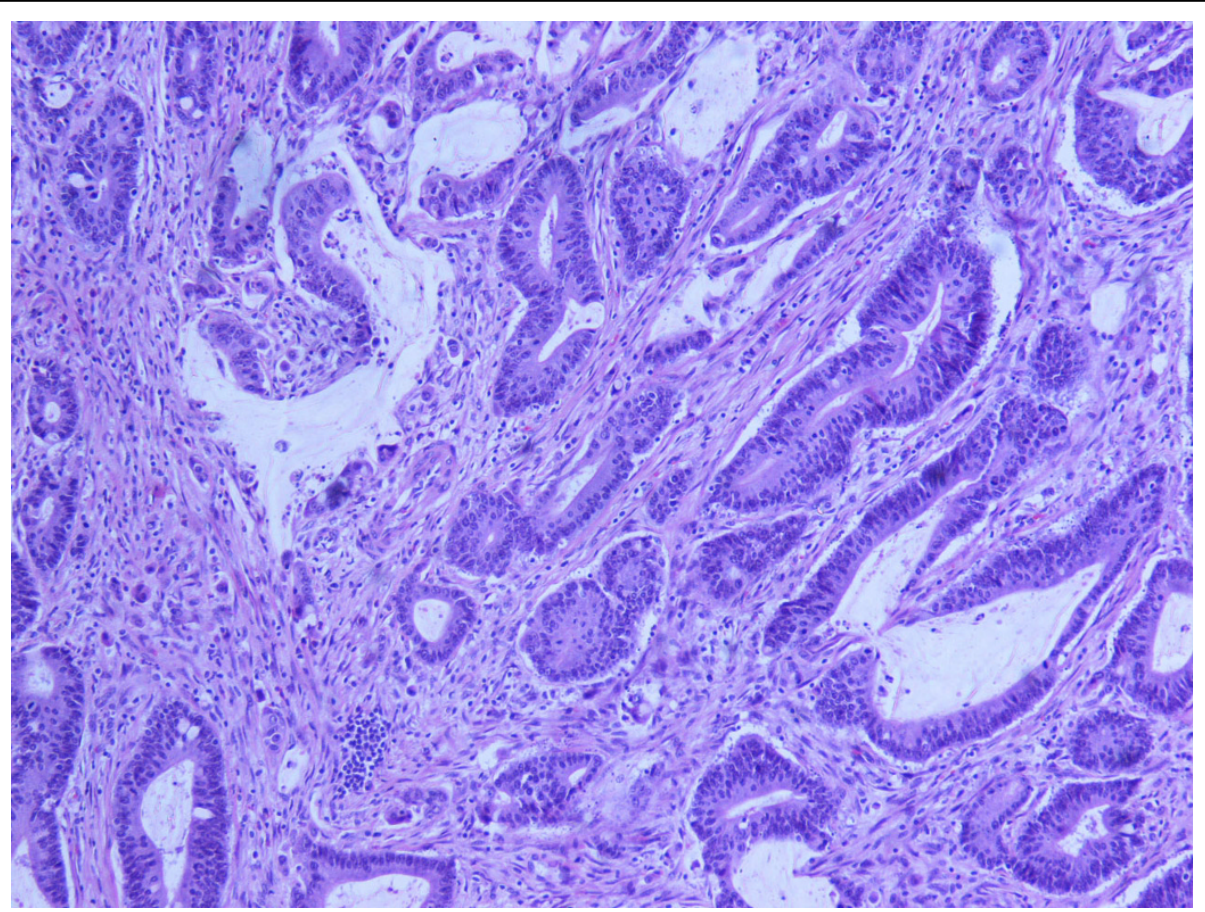

Figure 1 Moderately differentiated adenocarcinoma $(\mathrm{HE} \times \mathbf{2 0 0})$. The glands are lined by neoplastic cells with hyperchromatic nuclei. The tumor was accompanied with small mucinous lakes lind by well-differentiated epithelial cells. The tumor invades all intestinal wall.

of the specimen revealed a moderately differentiated mucus-producing adenocarcinoma, $3 \mathrm{~cm}$ in diameter located $5 \mathrm{~cm}$ from the peripheral surgical margin (figure $1)$. The tumor invaded into but not beyond the muscularis propria (T2). Ki 67 antigen and p53 tumor suppressor protein staining were positive and epidermal growth factor receptor (EGFR) negative. The left ovary was free of neoplasmatic tissue. Only four lymph nodes were counted, free of metastatic adenocarcinoma. The patient had an uneventful recovery. On rectum examination one year later a palpable extramucosal mass was noticed at the anterior rectum wall. An abdominal CT scan revealed a tumor $2 \mathrm{~cm}$ in size at the lower anterior mesorectum in close relation with the posterior vaginal wall and a second mass $2 \mathrm{~cm}$ in size at the anterior abdominal wall midline (figure 2, 3). Total colonoscopy showed no mucosal lesion. A chest $\mathrm{x}$-ray was normal. Rectal endoscopic ultrasound (EUS) showed a tumor infiltrating the rectum muscularis propria from outside. Core needle biopsy demonstrated the presence of a mucus producing adenocarcinoma with the same histological futures with the primary tumor and therefore it was considered as metachronous metastasis. Serum carcinoembryonic antigen level was normal. Since no other site of recurrence was identified, an abdominoperineal resection was attempted [5]. At laparotomy, the anterior abdominal wall mass was located at the site of previous incision and after complete resection, fast biopsy showed adenocarcinoma. Surgical examination of the abdominal cavity showed no sign of reccurence. At that time, sinus bradycardia and ST segment depression was noticed on electrocardiogram (ECG) monitoring. The termination of the operation was decided and a loop transverse colostomy was immediately perfomed. Postoperative cardiologic examination revealed an acute muocardium infract and the patient was treated respectively. Chemoradiation of the mesorectum tumor and re-evaluation for surgical excision was decided and she was discharged on the eleventh post operative day.

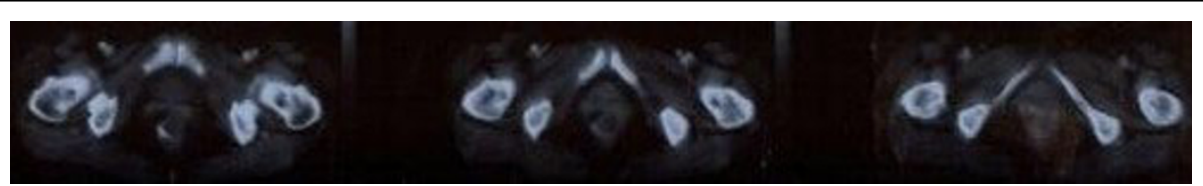

Figure 2 A pelvic CT showed a tumor $2 \mathrm{~cm}$ in size at the lower anterior mesorectum 


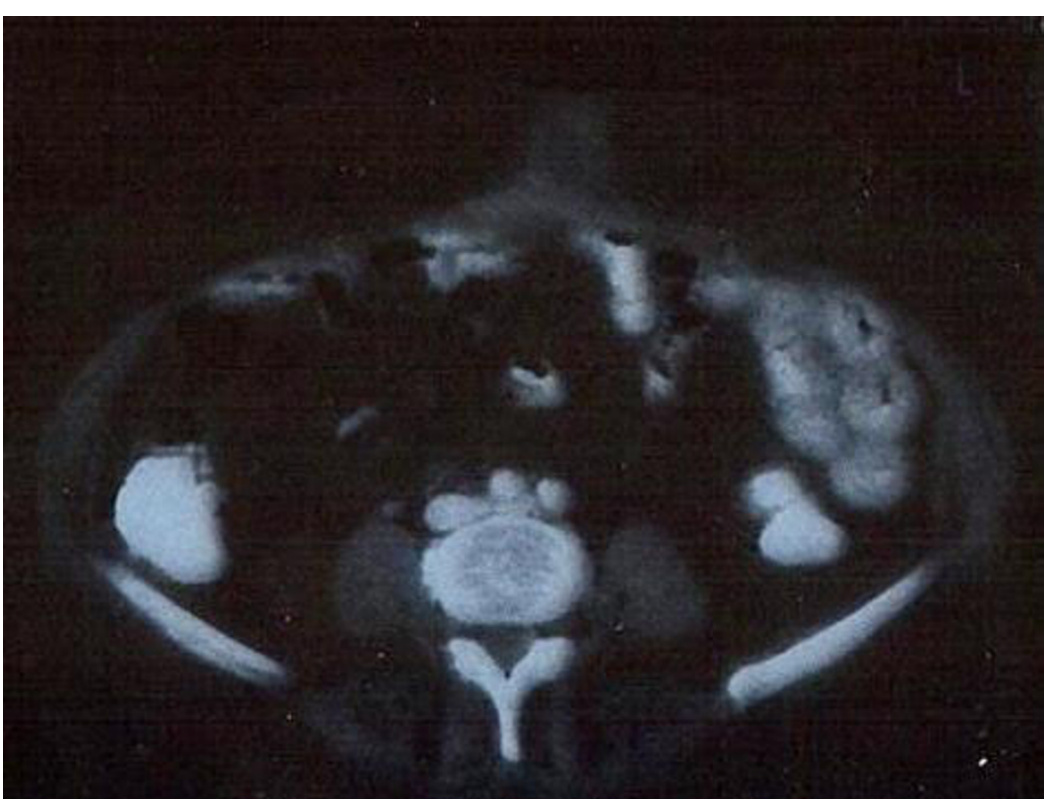

Figure 3 an Abdominal CT showed enhanced wall thickening in the anterior wall midline.

\section{Conclusion}

Recurrence after curative resection of colon adenocarcinoma is a major determinant of survival and it seems to increase as the primary tumor stage advance. In this case, a sigmoid adenocarcinoma is infiltrating $2 / 3$ of muscularis propria with four lymph nodes harvested free of metastatic disease. According to TNM classification this is a stage I (TINO M0) colon cancer but with inadequate lymph node evaluation [6-8]. Even though the literature lacks consensus as to what the exact number of lymph nodes by stage should be, a minimal number of twelve lymph nodes is recommended [9-13]. Nevertheless, metachronous metastasis to the mesorectum of a moderately differentiated T2 sigmoid adenocarcinoma with adequate peripheral surgical margin is extremely rare. The pathway tumor cells followed is unknown but one could suspect lymphatic spread. This is justified by the inadequate lymph node excision. But even if this is true, downward lymphatic flow is not common $[14,15]$. Recently, lymphatic spread from rectal cancer to the sigmoid colon lymph nodes was demonstrated in as much as $20 \%$ [16]. It seems that lymph flow is not only towards the paraortic lymph nodes but follows a more diffuse pattern. In addition, it is known that wound recurrence incidence is less than $1 \%$ and is probably a result of implanted cancer cells on the surgical wound during removal of the surgical specimen [17].

This case is important in showing that metachronous metastasis of the mesorectum from sigmoid colon cancer is possible, probably due to downward lymphatic cancer spread. Perhaps, there is a need of a more thorough investigation of the mesorectum region in sigmoid colon cancer during preoperative imaging. There is no similar report published in the literature.

\section{Consent}

Written informed consent was obtained from the patient for publication of this case report and any accompanying images. A copy of the written consent is available for review by the Editor-in-Chief of this journal.

Acknowledgements

To $\mathrm{AH}$ and NP for their general contribution in writing this manuscript.

\section{Authors' contributions}

JK first noticed this rare case report and wrote the main manuscript. GF revised the manuscript for important intellectual content. AM has been involved in drafting the manuscript. AZS performed histological examination of the specimens. SR has given final approval of the version to be published.

\section{Competing interests}

The authors declare that they have no competing interests.

Received: 2 January 2010 Accepted: 21 March 2010

Published: 21 March 2010

\section{References}

1. Hoshino S, Yanauchi K, Mikami T, Shinohara T: Evaluation of risk factors for metachronous liver and lung metastasis in colorectal carcinoma. Med Bull Fukuoka Univ 2007, 34(4):279-283.

2. Rasim Gencosmanoglu, Fugen Aker, Gozde Kir, Nurdan Tozun: Isolated metachronous splenic metastasis from synchronous colon cancer. World J Surg Oncol 2006, 4:42.

3. Shirakawa S, Kaneda K, Fujiwara H, Nishimura T, Sendo H, Wada T, Kizaki T: Case of a sigmoid colon cancer with metachronous metastases of the stomach and the abdominal wall. Nippon Shokakibyo Gakkai Zasshi 2009, 106(5):653-9. 
4. Mesko TW, Friedman J, Sendzischew H, Nixon DD: Rectal carcinoma metastatic to the thyroid gland. J Laryngol Otol 1996, 110(2):192-5

5. Goldberg RM, Fleming TR, Tangen CM, Moertel CG, Macdonald JS, Haller DG, Laurie JA: Surgery for recurrent colon cancer: strategies for identifying resectable recurrence and success rates after resection. Eastern Cooperative Oncology Group, the North Central Cancer Treatment Group, and the Southwest Oncology Group. Ann Intern Med 1998, 129(1):27-35.

6. NCCN Clinical Practice Guidelines in Oncology ColonCancer V.3.2009. .

7. Compton CC, Greene FL: The staging of colorectal cancer: 2004 and beyond. Ca Cancer J Clin 2004, 54:295-308.

8. International Union Against Cancer (UICC): Colon and rectum. TNM classification of malignant tumors New York, NY: WileySobin LH, Wittekind $\mathrm{CH}, 6$ 2002, 72-76.

9. Compton CC, Fielding LP, Burgardt LJ, Conley B, Cooper HS, Hamilton SR, Hammond ME, Henson DE, Hutter RV, Nagle RB, Nielsen ML, Sargent DJ, Taylor CR, Welton M, Willett C: Prognostic factors in colorectal cancer. College of American pathologists consensus statement. Arch Pathol Lab Med 2000, 124:979-994.

10. Sobin HL, Greene FL: TNM classification. Clarification of number of regional lymph node for pNO. Cancer 2001, 92(2):452.

11. Le Voyer TE, Sigurdson ER, Hanlon AL, Mayer RJ, Macdonald JS, Catalano PJ Haller DG: Colon cancer survival is associated with increasing number of lunph nodes analyzed: a secondary survey of intergroup trial INT-0089. $J$ Clin Oncol 2003, 21:2912-2919.

12. Chaplin S, Scerottini G-P, Bosman F-T, Konstanda MT, Givel J-C: For patients with Duke's B (TNM stage II) colorectal carcinoma, examination of six or fewer lymph nodes is related to poor prognosis. Cancer 1998, 83:666-72.

13. Joseph NE, Sigurdson ER, Hanlon AL, Wang H, Mayer RJ, MacDonald JS, Catalano PJ, Haller DG: Accuracy of determining nodal negativity in colorectal cancer on the basis of number of nodes retrieved on resection

14. Kobayashi Y, Fujita S, Yamaguchi T, Yamamoto S, Akasu T, Moriya Y: Optimum lymph node dissection in clinical T1 and clinical T2 colorectal cancer. Dis Colon Rectum 2009, 52(5):942-9.

15. Canessa CE, Badía F, Fierro S, Fiol V, Háyek G: Anatomic study of the lymph nodes of the mesorectum. Dis Colon Rectum 2001, 44(9):1333-6.

16. Park IJ, Choi GS, Lim KH, Kang BM, Jun SH: Metastasis to the sigmoid or sigmoid mesenteric lymph nodes from rectal cancer. Ann Surg 2009, 249:960-964.

17. Reilly WT, Nelson H, Schroeder G, Wieand HS, Bolton J, O'Connell MJ: Wound recurrence following conventional treatment of colorectal cancer. A rare but perhaps underestimated problem. Dis Colon Rectum 1996, 39(2):200-7.

doi:10.1186/1477-7819-8-17

Cite this article as: Kalaitzis et al:: Case of a sigmoid colon cancer with metachronous metastases to the mesorectum and the abdominal wall. World Journal of Surgical Oncology 2010 8:17.

\section{Submit your next manuscript to BioMed Central and take full advantage of:}

- Convenient online submission

- Thorough peer review

- No space constraints or color figure charges

- Immediate publication on acceptance

- Inclusion in PubMed, CAS, Scopus and Google Scholar

- Research which is freely available for redistribution

Submit your manuscript at www.biomedcentral.com/submit
C Biomed Central 